\title{
Subspecialty training in Ophthalmology; How far?
}

\author{
Kehinde Fasasi Monsudi ${ }^{1}$, Abayomi Olusola Ayodapo ${ }^{2}$ \\ ${ }^{1}$ Department of Ophthalmology, Federal Medical Centre, Birnin Kebbi, Kebbi State.Nigeria. \\ ${ }^{2}$ Department of Family Medicine, University College Hospital, Ibadan Oyo State, Nigeria.
}

\begin{tabular}{l|l|l} 
Corresponding author: Dr. Monsudi Kehinde Fasasi & Email: kfmoshood@yahoo.com & Phone: +2348027938305
\end{tabular}

\section{Introduction}

Globally, in the last 20years ophthalmology training have undergo a lot of reorganisation so as to be able to face the challenges of this century. This restructuring has led to the development of various subspecialties such as anterior segment, glaucoma, vitreoretinal, oculoplastics, uveitis and ocular immunology, paediatric ophthalmology and strabismus, community ophthalmology, neuro-ophthalmology, medical retinal, low vision and ophthalmic pathology. These subspecialties have resulted in better service delivery and better management of the populace in need resulting in reduction of blindness, morbidity and mortality from ocular pathology. Subspecialty ophthalmologist have better in-depth knowledge and management in the given area than general ophthalmologist ${ }^{1}$.

In Nigeria, ophthalmology subspecialty commenced in $2005^{2}$. The ophthalmology subspecialty program has resulted in the growth of the ophthalmology world-wide. However, medical students and freshly graduated doctors' awareness about these subspecialties in ophthalmology was poor talk less of non-medical personnel (general population) ${ }^{3}$.
In Nigeria, undergraduate medical students are mandated to do posting in ophthalmology department according to the medical curriculum. The duration of rotation ranges from 2 weeks to 1 month depending on the university ${ }^{1,3}$. This limited exposure result in poor understanding and poor grasp of the importance of ophthalmology in medicine and consequently left them with no passion to choose ophthalmology as a career.

However, in the past five years, things have improved as there is increased exposure of medical doctors to the specialty of ophthalmology. There is a mandatory one week posting in ophthalmology for every newly graduated medical doctor during house job (internship) and mandatory 4 weeks rotation posting in ophthalmology by resident doctors in the department of Family Medicine ${ }^{4}$.

These increased exposure in undergraduate, during internship and post graduate medical training and formation of various ophthalmology subspecialties have open the gate for uptake of ophthalmology as a carer among Nigeria doctors.

Some years back in Nigeria resident doctors enrol for training in ophthalmology because of the

\footnotetext{
Musa KO, Aribaba OT, Samuel AR, Oluleye TS, Idowu OO. Subspecialty preferences among ophthalmology resident doctors in Nigeria. NJO 2012; 25(2): 123-128 Ogun OA. Encouraging subspecialty practice by constructivelyin uencing trainees early in their careers will improve advocacyfor neuro-ophthalmology among Nigerian ophthalmologists. JMed Educ Curric Dev. 2016;3:149-55.

Adeboye A, Ayanniyi AA, Ademola-Popoola DS, Owoeye JF. The Choice of Ophthalmology as a Career among Nigeria Medical Interns. African Journal of Medicine and Medical Science. 2006; 35(3): 321-323

WACS Faculty of Ophthalmology training curriculum for the fellowship programme https://www.wacscoac.org/downloads/WACS\%20OPH\%20FELL\%20CURR.pdf Accessed 15th May 2021

Ezisi CN, Arinze OC, Oguego NC, Ogbonnaya CE, Ezeanosike E. Subspecialist eye care services in Nigeria: Current Status and Challenges. East African Medical Journal. 2019; 96(6)
} 
difficulty in getting a slot in other post graduate medical programme. However recently the trends have changed as it is increasingly becoming difficult to get enrol into ophthalmology training programme because of few slots and training centres available. However, the increased enrolment into postgraduate training in ophthalmology does not translate same to training in subspecialty.

Uptake of subspecialties in ophthalmology has increased in the last 5years due to the support of Federal ministry of health, National Postgraduate Medical College of Nigeria (NPMCN), West African Postgraduate College of Surgeon (WACS), Ophthalmological Society of Nigeria (OSN) and different local and international Non-Governmental Organisation(NGOs) ${ }^{4}$. Despite the help received by the above organisations, most young ophthalmologists are not grabbing this opportunity with enthusiasm, and this calls for concern.

\section{Why young ophthalmologists do not want to do ophthalmology subspecialty training?}

1. The long duration of training before qualifying as a fellow is the main reason young ophthalmologists are unwilling to go for subspecialty. In Nigeria years spent to complete ophthalmology fellowship program is a minimum of $5 \frac{1}{2}$ years. After this the fellow will spend another $1-2$ years to have subspecialty training ${ }^{4}$.

2. The stress and fatigue that characterise fellowship training discourage some young ophthalmologist to enrol for subspecialty training. They can't imagine subjecting themselves to such similar tiring training again.

3. The cost of training for Fellowship as a resident doctor is enormous (out of pocket spending on revision courses, examination fees etc.). Subjecting themselves to another training with huge cost implication is discouraging despite the support few organisations are ready to offer to few selected intended trainees ${ }^{2,5}$.

4. Lack of adequate equipment at ophthalmology training centres ${ }^{5}$.

5. Poor remuneration and somersaulting health policy by government (Federal and State)

6. Recently, National University Commission (NUC) policy of acquisition of $\mathrm{PhD}$ before you can lecture in the university and has career advancement is a big blow and demoralising. Pursing $\mathrm{PhD}$ program will be preferred to additional years in subspecialty training in ophthalmology.

7. Dearth of ophthalmologist subspecialty trainer in Nigeria, hence making it difficult to start all areas of subspecialty training program e.g ophthalmology pathology and uveitis subspecialty ${ }^{5}$.

\section{Highlighted below are few recommendations to solve these challenges:}

1. Creation of awareness about subspecialty at undergraduate and during postgraduate medical training is key to encourage enrolment in subspecialty ophthalmology training.

2. Reduction in the year of training of both fellowship and subspecialty program by both NPMCN AND WACS. Combining the training (fellowship and subspecialty program) to run just like what is been practice in India and other countries will go a long way in enrolment for subspecialty training program.

3. Restructuring of NPMCN and WACS postgraduate medical curriculum to allow easy

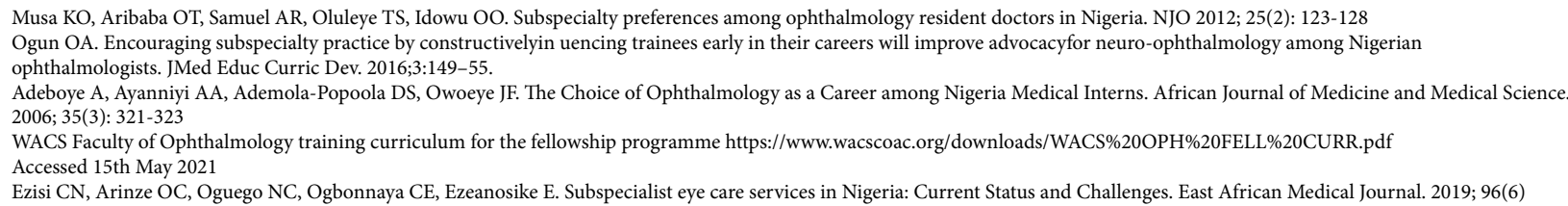


enrolment for training and timely exit from the program.

4. Creation of more ophthalmology training centres and investment in the purchase of adequate and state of the art facilities and equipment through the government support (State and Federal).

5. Regular stakeholders meeting between OSN, NPMCN, ministry of health and NGOs to appraise training in Ophthalmology in Nigeria.

6. Rolling out exchange program between ophthalmology training centre in Nigeria and the Western world for the purpose of exposure and skills acquisition.

7. Improved remuneration for doctors and provision of insurance.

8. Government sponsorship in conjunction with OSN in training young ophthalmologist for subspecialty ophthalmology abroad will help in the development of human capacity. Their skills will be useful when they return to Nigeria and help in setting up standard subspecialty ophthalmology training centres.

9. Mentoring of young ophthalmologist by senior ophthalmologist should not be ignored too.

10. The publication arm of OSN (Nigeria Journal of Ophthalmology) should create awareness about career building opportunity in subspecialty and super specialty areas in Ophthalmology in one of the editions of the journal.

We conclude that skills acquisition in subspecialty areas of ophthalmology will help in reducing ocular morbidity and mortality in Nigeria, as been experience in the developed countries. Hence young Nigeria ophthalmologist should be encouraged to undergo subspecialty training. Stakeholders in eye care services delivery should come together to develop this important training program with needed resources. 